\title{
Separation and purification of curcumin using novel aqueous two-phase micellar systems composed of amphiphilic copolymer and cholinium ionic liquids
}

\author{
Isabelle S. Kurnik ${ }^{\mathrm{a}}$, Mariana A. Noronha ${ }^{\mathrm{b}}$, Mayra C.C. Câmara ${ }^{\mathrm{b}}$, Priscila G. Mazzola ${ }^{\mathrm{b}}$, \\ António A. Vicente ${ }^{c}$, Jorge F.B. Pereira ${ }^{\mathrm{a}, \mathrm{d}, *}$, André M. Lopes ${ }^{\mathrm{b}, *}$ \\ ${ }^{a}$ Department of Engineering Bioprocesses and Biotechnology, School of Pharmaceutical Sciences, São Paulo State University (UNESP), Araraquara, SP, Brazil \\ ${ }^{\mathrm{b}}$ Faculty of Pharmaceutical Sciences, University of Campinas, Campinas, SP, Brazil \\ ${ }^{\mathrm{c}}$ Centre of Biological Engineering (CEB), University of Minho, Campus de Gualtar, 4710-057 Braga, Portugal \\ d Univ Coimbra, CIEPQPF, Department of Chemical Engineering, Rua Sílvio Lima, Pólo II - Pinhal de Marrocos, 3030-790 Coimbra, Portugal
}

\section{A R T I C L E I N F O}

\section{Keywords:}

curcumin (CCM)

separation

Pluronic F68

polymeric micelles (PMs)

aqueous two-phase micellar systems (ATPMS)

ionic liquids (ILs)

\begin{abstract}
A B S T R A C T
Novel aqueous two-phase micellar systems (ATPMS) composed of Pluronic F68, a triblock amphiphilic copolymer, and cholinium-based ionic liquids (ILs) were formulated and applied for separation/purification of curcumin (CCM). CCM stability in the presence of ATPMS components was also evaluated. CCM is stable up to $24 \mathrm{~h}$ in copolymer $(1.0-10.0 \mathrm{wt} \%)$ and ILs $(0.1-3.0 \mathrm{M})$ aqueous solutions. Very mild phase separation conditions (close to room temperature) were achieved by adding cholinium ILs to the Pluronic F68 + McIlvaine buffer at $\mathrm{pH} 6.0$ solution. The decrease of cloud-point temperature is dependent on the relative hydrophobicity of IL anion, $[\mathrm{Hex}]^{-}>[\mathrm{But}]^{-}>[\mathrm{Pro}]^{-}>[\mathrm{Ac}]^{-}>\mathrm{Cl}^{-}$. ATPMS composed of more hydrophobic ILs ([Ch] $[\mathrm{Hex}]>[\mathrm{Ch}][\mathrm{But}]>[\mathrm{Ch}][$ Pro] $)$ are most efficient in the partition of commercial CCM into polymeric micelles (PMs)-rich phase. The best ATPMS (0.70 M [Ch][But] and $0.60 \mathrm{M}$ [Ch][Hex]-based ATPMS) were then used to purify CCM from a crude extract of Curcuma longa L. Both systems were very selective to separate CCM from protein-based contaminants (selectivity values $\geq 25$; purification yields $\geq 12$-fold). Pluronic F68-based ATPMS are promising for selective separation of hydrophobic biomolecules by using cholinium-based ILs as adjuvants to adjust phase separation temperatures and biomolecules' partition.
\end{abstract}

\section{Introduction}

Ionic liquid (IL)-based aqueous two-phase systems (ATPS) have shown an extremely fast progress, mainly because of biocompatible gains over conventional liquid - liquid extraction platforms $[1,2]$. The potential of IL-based ATPS for selective extraction/separation of a plethora of molecules/biomolecules was mostly a result of their flexibility and adjustability by a proper choice of the structure of phaseforming compounds, which can also boost ATPS' biocompatibility and lipophilic-hydrophilic range [1-4]. Outstanding performances for extraction and purification of several biological/pharmaceutical active substances were already reported $[1,5,6]$.

From the plethora of ATPS available, a growing interest on systems that use amphiphilic polymers as phase forming compounds has been observed $[7,8]$. The use of copolymers on developing IL-based ATPS is an interesting approach to design "more tunable" and selective systems, mainly envisaging the separation of structurally similar and/or more hydrophobic molecules. The class of ABA triblock copolymers, commercially available as Pluronic, offers a pool of $>50$ amphiphilic compounds as pharmaceutical excipients under the US and British Pharmacopeia criteria [9]. These copolymers are thermoresponsive, offering extra tunable characteristics, very attractive for the biopharmaceutical area [9-11]. Pluronic copolymers are water-soluble, polymorphic materials $(\mathrm{A}=$ hydrophilic block poly(ethylene oxide) (PEO) and B = hydrophobic block poly(propylene oxide) (PPO)), with lower critical solution temperature (LCST) in water, forming a biphasic regime composed of a polymeric micelles (PMs)-rich phase and a PMspoor phase - commonly categorized as aqueous two-phase micellar systems (ATPMS) [12].

The use of copolymers in the biphasic aqueous formulations is

\footnotetext{
* Corresponding authors at: Univ Coimbra, CIEPQPF, Department of Chemical Engineering, Rua Sílvio Lima, Pólo II - Pinhal de Marrocos, 3030-790 Coimbra, Portugal (Jorge F.B. Pereira). Faculty of Pharmaceutical Sciences, University of Campinas, Campinas, SP, Brazil (André M. Lopes).

E-mail addresses: jfbpereira@eq.uc.pt (J.F.B. Pereira), amlopes@unicamp.br (A.M. Lopes).
} 
supported for their: (i) capacity to obtain intermediate degrees of hydrophobicity [13]; (ii) higher biocompatible character [14]; (iii) amphiphilic nature, that enables the solubilization of hydrophobic molecules [11]; (iv) thermosensitivity, that facilitates recovery and reuse procedures [15]; $(v)$ ability to form mixed micelles to purify targetmolecules, and/or remove contaminants [16]; (vi) capability to encapsulate drugs in a polymeric (or micellar) matrix [17].

Because of countless health benefits (e.g. anti-inflammatory, free radical scavenging, antimicrobial, and anticancer activities) of curcumin (CCM)-related bioactive compounds (like curcuminoids from turmeric (Curcuma longa L.) spice [18]), the interest of nutraceutical and pharmaceutical industries on these has been growing [19-21]. Nowadays, the extraction of curcuminoids from biological sources is mostly based on solid-liquid and liquid-liquid platforms using volatile organic solvents (VOCs) [22,23], while the subsequent purification is performed by applying sequential chromatography units. Current extraction platforms exhibit several environmental and health concerns associated to the use of VOCs as major solvents (e.g., toxicity; flammability; denaturing effect and waste disposal) $[24,25]$. Chromatographic processes are still very challenging, complex and expensive; for example, the structural similarity of curcuminoids forces coupling these methods with additional separation techniques to enhance the resolution power $[18,22]$. Although the scientific community has been concerned with these aspects for the separation and purification of curcuminoids, the number of works in that field is still rather scarce. An exception is the work of Silva et al. [8] that used Pluronic L35 $\left(\mathrm{PEO}_{11^{-}}\right.$ $\mathrm{PPO}_{16}-\mathrm{PEO}_{11}$ )-based ATPS for a selective separation of two structural similar flavonoids (naringin and rutin) by using cholinium bicarbonate as additive.

In order to overcome some of the issues of current CCM downstream processing, this work proposes a novel and simple process based on the application of Pluronic-based ATPMS. Novel ATPMS composed of Pluronic $\mathrm{F} 68\left(\mathrm{PEO}_{76}-\mathrm{PPO}_{29}-\mathrm{PEO}_{76}\right)$ and cholinium-based ILs as adjuvants were formulated. In order to gather insights on how to design selective Pluronic F68 ATPMS-mediated downstream processes, the CCM stability (in the presence of phase-forming components) and partition using these ATPMS were evaluated. CCM, a yellow colored crystalline polyphenol, was chosen for the partition studies, because it is one of the major curcuminoids found in C. longa L. (typically about $75 \%$ [26]), with very relevant challenges regarding its extraction/ purification. Additionally, CCM has a poor solubility in aqueous environments, representing an interesting model biomolecule for the development of alternative downstream processes for the purification of hydrophobic bioactive compounds of pharmaceutical interest. The potential of the best ILs-based ATPMS for the purification of CCM from a crude extract of $C$. longa L. was also evaluated.

\section{Material and methods}

\subsection{Material}

Pluronic ${ }^{\circledR}$ F68 (composed by $\mathrm{PEO}_{76}-\mathrm{PPO}_{29}-\mathrm{PEO}_{76}, \mathrm{M}_{\mathrm{W}} \approx 8,400 \mathrm{~g} /$ $\mathrm{mol}$ ), and pure commercial curcumin (CCM, purity > $\mathrm{M}_{\mathrm{W}} \approx 368.38 \mathrm{~g} / \mathrm{mol}$ ) were purchased from Sigma-Aldrich (St. Louis, MO, USA). The powdered material dried from Curcuma longa L. rhizomes (i.e., crude sample) was purchased from Kitano ${ }^{\circledR}$ (Cambará, PR, Brazil, Lot \#L19BRPP052). The samples were stored sheltered from light and moisture before their use in the extraction studies. ILs used in this study - cholinium chloride $([\mathrm{Ch}] \mathrm{Cl})$, cholinium acetate $([\mathrm{Ch}][\mathrm{Ac}])$, cholinium propanoate ([Ch][Pro]), cholinium butanoate ([Ch][But]), and cholinium hexanoate $([\mathrm{Ch}][\mathrm{Hex}])$ - were synthesized by us according to previous protocols [27]. The purity and chemical structures of Pluronic F68 and ILs are shown in Table 1. Aqueous solutions of all components were prepared in McIlvaine buffer (composed of $\mathrm{K}_{2} \mathrm{HPO}_{4} \cdot 3 \mathrm{H}_{2} \mathrm{O}+\mathrm{C}_{6} \mathrm{H}_{8} \mathrm{O}_{7} \cdot \mathrm{H}_{2} \mathrm{O}$ ) with distinct $\mathrm{pH}$ values (6, 7, and 8), using ultrapure water from Millipore Milli-Q system (Bedford, MA). All other reagents were of analytical grade and used as received.

\subsection{Determination of the phase diagrams}

The binodal curves for the systems composed of Pluronic F68/ Mcllvaine buffer ( $\mathrm{pH}$ 6.0) in the presence of ILs (concentration of IL varied from 0.1 to $3.0 \mathrm{M}$ ) were obtained through the cloud-point titration method [28]. Briefly, Pluronic F68 buffered solutions of known concentrations (with/without ILs) were added to graded glass tubes $(15 \mathrm{~mL})$ and placed in a transparent thermo-regulated device (Polyscience, model 9505). Temperature control was achieved (accuracy \pm $0.015{ }^{\circ} \mathrm{C}$ ) with a thermometer (Omega ${ }^{\circledR}$, model HH40) coupled to a thermistor probe (Omega ${ }^{\circledR}$, model ON-403-PP). Magnetic stirring was applied to ensure temperature and concentration homogeneity. The temperature was first lowered until the solution exhibited a clear monophasic phase, and then slowly raised (increase step of $0.1{ }^{\circ} \mathrm{C}$ ) until the solution became cloudy. This temperature was recorded as the phase separation (cloud-point) temperature $\left(T_{\mathrm{CP}}\right)$. The procedure was performed in triplicate, and the corresponding binodal curve was determined by plotting the mean of $T_{\mathrm{CP}}$ values as a function of Pluronic F68 concentration (wt $\%$ ).

\subsection{CCM stability studies}

Before carrying out CCM partition studies, preliminary stability studies were performed to define working experimental windows. The stability of pure commercial CCM at various $\mathrm{pH}$ values $(6.0,7.0$, and 8.0) and temperatures $\left(30,50\right.$, and $\left.70{ }^{\circ} \mathrm{C}\right)$ was first evaluated up to $72 \mathrm{~h}$. Subsequently, the CCM stability in the presence of aqueous (McIlvaine buffer at pH 6.0 - most stable $\mathrm{pH}$ ) solutions of Pluronic F68 (1.0 and $10.0 \mathrm{wt} \%)$ and each IL $(0.1$ and $3.0 \mathrm{M})$, during $24 \mathrm{~h}$ of incubation, was determined.

For all stability studies, aqueous solutions containing Pluronic F68, IL or Mcllvaine buffer, with an initial CCM concentration of $0.5 \mathrm{mg} / \mathrm{mL}$ were prepared. Aqueous solutions were then homogenized according to the procedure detailed in Section 2.4. During incubation, aliquots were withdrawn, and the respective concentration of CCM determined as described in Section 2.5.

CCM stability percentage $\left(C C M_{\text {stb }}\right)$ was calculated according to Eq. (1):

$C C M_{\text {stb }}(\%)=\frac{[\mathrm{CCM}]_{\text {after }}}{[\mathrm{CCM}]_{\text {before }}} \times 100$

where $[\mathrm{CCM}]_{\text {after }}$ and $[\mathrm{CCM}]_{\text {before }}$ correspond to CCM concentration in the sample after and before (initial concentration) incubation, respectively.

\subsection{Partition/purification studies of CCM using ATPMS}

For partition and separation studies, $6.0 \mathrm{~g}\left( \pm 10^{-4} \mathrm{~g}\right)$ aqueous buffered systems were prepared in graduated test tubes $(15 \mathrm{~mL})$ by adding known amounts of Pluronic F68, IL and McIlvaine buffer (pH 6.0). Afterwards, $3.5 \mathrm{mg}$ of pure commercial CCM (partition) or CCM from crude sample (purification) were added to each system. Since CCM is light-sensitive and relatively pH unstable [29], all assays were performed in dark rooms, under $\mathrm{pH}$ monitoring.

ATPMS were then homogenized in an orbital shaker (Barnstead/ Thermolyne, model 400110) at $15 \mathrm{rpm}$ for $60 \mathrm{~min}$, followed by sonication at $50 \mathrm{~W}$ for $45 \mathrm{~min}$ at $30{ }^{\circ} \mathrm{C}$ (ultrasound bath Qsonica ${ }^{\circledR}$ ), and equilibrated at $5{ }^{\circ} \mathrm{C}\left( \pm 0.15{ }^{\circ} \mathrm{C}\right)$. In order to form a biphasic regime, each ATPMS was placed in a thermoregulated device (Polyscience, model 9505), at a pre-defined temperature (Table 2), during $3 \mathrm{~h}$. After the equilibrium, the two coexisting (polymeric micelle (PMs)-rich and -poor) phases were carefully separated using disposable syringes and needles, and the respective CCM concentration was determined. CCM purification studies from crude extract of C. longa L. were only 
Table 1

Chemical structure, name, abbreviation, and purity of Pluronic F68 and cholinium-based ionic liquids (ILs).

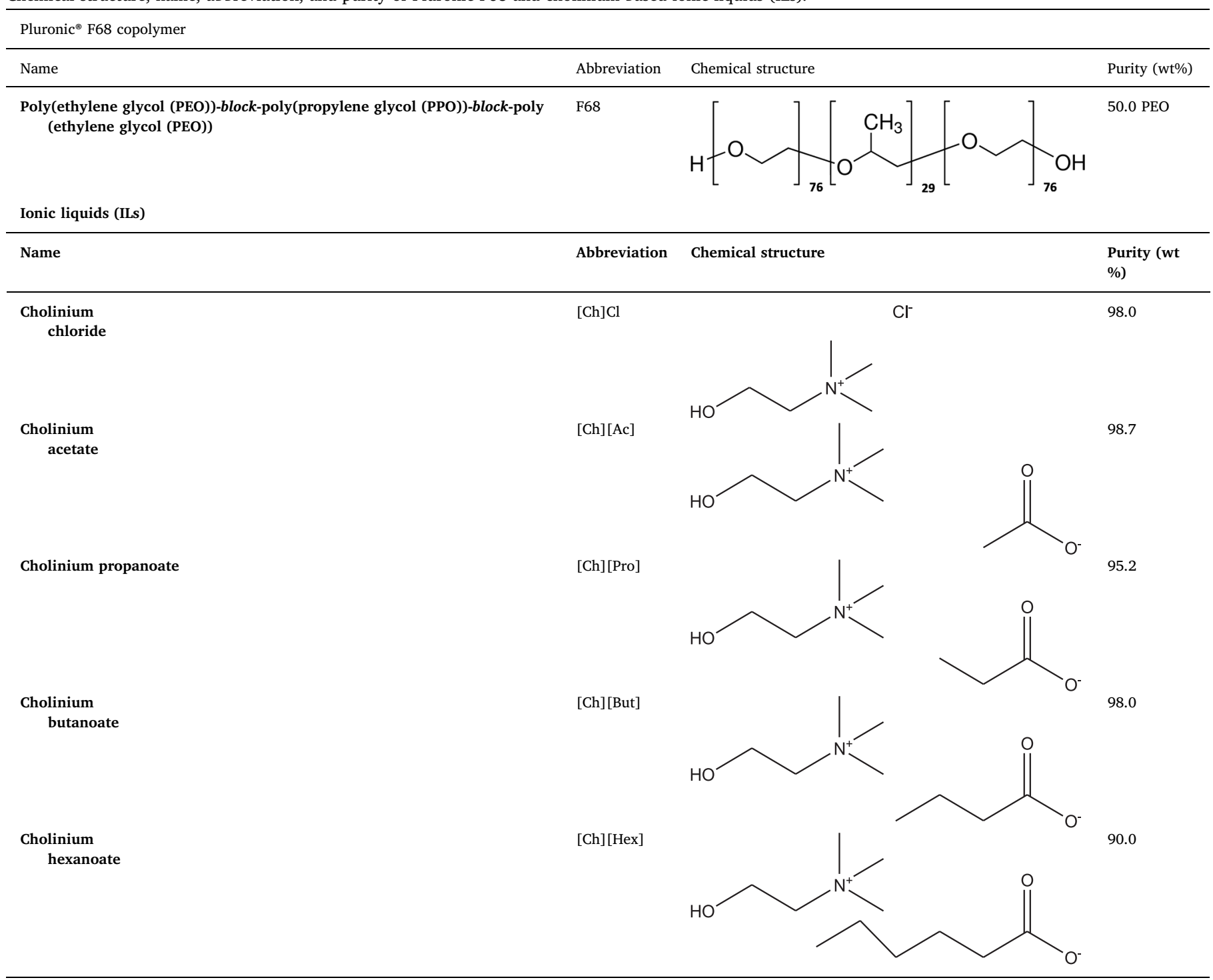

Table 2

Experimental compositions and temperatures used in the partition of curcumin (CCM) with Pluronic F68/McIlvaine buffer (pH 6.0) + ionic liquids (ILs)-based aqueous two-phase micellar systems (ATPMS).

\begin{tabular}{|c|c|c|c|}
\hline \multirow[t]{2}{*}{ Assays } & \multicolumn{2}{|l|}{ ATPMS } & \multirow[t]{2}{*}{$\mathrm{T}\left({ }^{\circ} \mathrm{C}\right)$} \\
\hline & [F68] $(\mathrm{wt} \%)$ & $*[\mathrm{ILs}](\mathrm{M})$ & \\
\hline 1 & 1.0 and 5.0 & $2.75 \mathrm{M}[\mathrm{Ch}] \mathrm{Cl}$ & 20 and 25 \\
\hline 2 & & $2.60 \mathrm{M}[\mathrm{Ch}][\mathrm{Ac}]$ & \\
\hline 3 & & $2.00 \mathrm{M}[\mathrm{Ch}][$ Pro $]$ & \\
\hline 4 & & $0.70 \mathrm{M}[\mathrm{Ch}][\mathrm{But}]$ & \\
\hline 5 & & $0.60 \mathrm{M}[\mathrm{Ch}][\mathrm{Hex}]$ & \\
\hline
\end{tabular}

* The binodal curves in the presence of ILs were experimentally obtained in the same region in order to guarantee the same tie-line, as well as the same polymeric micelles (PMs) concentration in the PMs-rich phase. For this reason, the ILs concentration evaluated were different between the assays.

performed for the two ATPMS with best partition performances. The experimental protocol was similar excepting that, in addition to the CCM concentration, the total protein content was also determined.

The partition performance was evaluated considering the following parameters: CCM partition coefficient $\left(K_{\mathrm{CCM}}\right)$, CCM mass balance $(M B)$, and percentage of CCM recovered in the PMs-rich and PMs-poor phases ( $R E C_{\text {Rich }}$, and $R E C_{\text {Poor }}$, respectively), as described in Equations (2) to (5), respectively:

$K_{\mathrm{CCM}}=\frac{[\mathrm{CCM}]_{\text {PMs-rich }}}{[\mathrm{CCM}]_{\text {PMs-poor }}}$

$M B(\%)=\left(\frac{[\mathrm{CCM}]_{\text {PMs-rich }} \mathrm{V}_{\mathrm{PMs}-\text { rich }}+[\mathrm{CCM}]_{\mathrm{PMs} \text {-poor }} \mathrm{V}_{\mathrm{PMs} \text {-poor }}}{[\mathrm{CCM}]_{\text {initial }} \mathrm{V}_{\text {initial }}}\right) \times 100$

$R E C_{\text {Rich }}(\%)=\left(\frac{[\mathrm{CCM}]_{\text {PMs-rich }} \mathrm{V}_{\text {PMs-rich }}}{[\mathrm{CCM}]_{\text {initial }} \mathrm{V}_{\text {initial }}}\right) \times 100$

$R E C_{\text {Poor }}(\%)=\left(\frac{[C C M]_{\text {PMs-poor }} \mathrm{V}_{\text {PMs-poor }}}{[\mathrm{CCM}]_{\text {initial }} \mathrm{V}_{\text {initial }}}\right) \times 100$

The performance of each ATPMS to purify CCM from crude extract of $C$. longa $\mathrm{L}$. was determined in terms of selectivity $(S)$ and purification factor $\left(P_{\mathrm{F}}\right)$ of CCM relatively to total protein contents (as contaminants), as described by Eqs. (6) and (7), respectively.

$S=\frac{K_{\mathrm{CCM}}}{K_{\mathrm{TP}}}$ 
where $K_{\mathrm{TP}}$ refer to total protein (TP) partition coefficient (like in Equation (2)).

$P_{\mathrm{F}}=\frac{\frac{[\mathrm{CCM}]_{\text {PMs-rich }}}{[\mathrm{TP}]_{\mathrm{PMs}-\text { rich }}}}{\frac{[\mathrm{CCM}]_{\text {initial }}}{[\mathrm{TP}]_{\text {initial }}}}$

where $[\mathrm{TP}]_{\mathrm{PMs} \text {-rich }}$ and $[\mathrm{TP}]_{\text {initial }}$ correspond to the concentration of total proteins in the PMs-rich phase and the initial total protein concentration in the system, respectively.

\subsection{Quantification of CCM concentration}

CCM concentration was determined by measuring the optical absorbance at a wavelength of $420 \mathrm{~nm}$ (Elisa Biotech Synergy HT UV-Vis spectrophotometer, Biotek, USA) using acetone and ultrapure water as blank samples. Absorbance values were correlated with CCM concentration based on a pre-established calibration curve $(0$ to $20 \mathrm{mg} / \mathrm{mL}$ of pure CCM).

\subsection{Quantification of total protein concentration}

Total protein concentration was determined through the bicinchoninic acid method (Pierce ${ }^{\mathrm{TM}}$ BCA Protein Assay Kit), according to the manufacturer's instructions. The protein was determined as visible optical absorbance at a wavelength of $562 \mathrm{~nm}$ by spectrophotometry (Elisa Biotech Synergy HT, Biotek, USA), using ultrapure water as blank. Absorbance values were correlated to protein concentration by using a pre-established calibration curve with bovine serum albumin (BSA) (0 to $1 \mathrm{mg} / \mathrm{mL}$ ).

\section{7. $p H$ and conductivity determination}

$\mathrm{pH}( \pm 0.03)$ values and conductivities were determined using a dual meter $\mathrm{pH}$ /conductivity device (Mettler Toledo, Columbus, $\mathrm{OH}$, USA; model MPC 227).

\subsection{Statistical analysis}

Data were collected from three independent experimental assays and presented as mean \pm standard error of the mean. $p$ values $<0.05$ were considered as statistically significant.

\section{Results and discussion}

\subsection{CCM stability studies}

In order to define the best processual conditions for partition studies, the CCM stability $\left(C C M_{\mathrm{stb}}\right)$ was determined at different $\mathrm{pH}$ values (6.0, 7.0, and 8.0) and temperatures $\left(30,50\right.$, and $\left.70{ }^{\circ} \mathrm{C}\right)$ over $72 \mathrm{~h}$ (Fig. 1a and 1b), as well as in the presence of aqueous solutions of Pluronic F68 (1.0 and 10.0 wt\%) and each IL (0.1 and 3.0 M) over $24 \mathrm{~h}$ (Fig. 2).

A general analysis of Fig. $1 \mathrm{a}$ and $1 \mathrm{~b}$ allows identifying two major trends, a pH-dependent $\left(C C M_{\mathrm{stb}, \mathrm{pH} 6.0}>C C M_{\mathrm{stb}, \mathrm{pH}} 7.0>C C M_{\mathrm{stb}} \mathrm{pH}\right.$ $\left.{ }_{8.0}\right)$ and a temperature-dependent $\left(C C M_{\text {stb, } 30{ }^{\circ} \mathrm{C}>C C M_{\text {stb }}, 50}\right.$ ${ }^{\circ} \mathrm{C}>C C M_{\text {stb, } 70}{ }^{\circ} \mathrm{C}$ ), respectively. Fig. 1a shows that CCM remains stable at acidic conditions ( $\mathrm{pH}$ 6.0) up to $72 \mathrm{~h}$ of incubation $\left(C C M_{\mathrm{stb}}\right.$ values $>90 \%$ ). The increase of the $\mathrm{pH}$ to 7.0 and 8.0 caused a considerable decrease of $C C M_{\text {stb }}$ (after $72 \mathrm{~h}-C C M_{\text {stb }}$ of 60 and 35\%), respectively. Wang et al. [30] also observed higher CCM degradation $(\approx$ $90 \%$ ) at physiological conditions (i.e., $0.1 \mathrm{M}$ phosphate buffer at $\mathrm{pH}$ 7.2) than under acidic $\mathrm{pH}$ conditions (3.0 to 6.0). Despite the lower CCM degradation rates (a maximum of $40 \%$ ), in comparison with Wang's study [30], the negative impact of $\mathrm{pH}$ increase is evident.

Regarding temperature influence (Fig. 1b), the incubation at a mild temperature, $30{ }^{\circ} \mathrm{C}$, maintained $C C M_{\text {stb }}(\approx 85 \%)$ up to $72 \mathrm{~h}$. However, an increase to 50 and $70{ }^{\circ} \mathrm{C}$ destabilized significantly the CCM, as demonstrated by $C C M_{\text {stb }}$ values close to 55 and $20 \%$, after $72 \mathrm{~h}$, respectively. A similar effect was observed by Wang et al. [31], when exposing $\mathrm{CCM}$ to $70{ }^{\circ} \mathrm{C}$ for $10 \mathrm{~min}$, obtaining a sharp decrease in its concentration. Suresh et al. [32] also observed losses of circa $53 \%$ of $C C M_{\text {stb }}$ as result of heating and pressure joint-effect (incubation at $100{ }^{\circ} \mathrm{C}, 15 \mathrm{psi}$ for $10 \mathrm{~min}$ ).

Fig. 2 depicts the $C C M_{\text {stb }}$ in the presence of ATPMS components. With the exception of small losses in the presence of $10.0 \mathrm{wt} \%$ Pluronic F68 at $30{ }^{\circ} \mathrm{C}$ and $24 \mathrm{~h}$ of incubation $\left(C C M_{\text {stb }} \approx 85 \%\right.$ ) (Fig. $2 \mathrm{a}$ ), CCM is highly stable in the presence of amphiphilic copolymer F68 buffer solutions, confirming the biocompatible and stabilization character of amphiphilic copolymers [9]. Similarly, as shown in Fig. 2b, all diluted aqueous solutions of cholinium ILs $(0.1 \mathrm{M})$ were very compatible with CCM. The increase of IL concentration decreased slightly the $C C M_{\mathrm{stb}}$, in particular, when the more hydrophobic ILs were added (Fig. 2c). For example, after $24 \mathrm{~h}$ of incubation at $30{ }^{\circ} \mathrm{C}$ with $3.0 \mathrm{M}$ of [Ch] [But] and [Ch][Hex] solutions, $C C M_{\text {stb }}$ decreased to values of 82 and $80 \%$, respectively. Anyway, these CCM losses are far less intense than those due to $\mathrm{pH}$ and temperature increases, confirming the biocompatible character of cholinium ILs. Recently, Magri et al. [33] demonstrated that cholinium ILs aqueous solutions maintain the enzymatic activity of Lasparaginase (ASNase). Similarly, $[\mathrm{Ch}] \mathrm{Cl}$ and [Ch] [Ac] have the most structural stabilizing aptitudes, while the increase of IL's anion alkyl chain length and temperature decreased the favorable stabilizing effects [33]. Like other polymers and ionic compounds [16,33,34], Pluronic F68 and cholinium-based ILs can be thus used as ATPMS-forming components, not only because of ATPMS formation but also for their biocompatible/stabilization characteristics.

\subsection{Pluronic F68 + ILs ATPMS phase diagrams}

The use of ionic adjuvants on the formation of ATPMS promotes electrostatic screening and, by modifying the inter- and intra-micellar interactions, it induces a subsequent change on phase separation temperature $[16,35,36]$. Therefore, if the ionic adjuvants decrease the $T_{\mathrm{CP}}$, the separation processes could be performed at lower temperatures, facilitating operational conditions and preventing the damage of thermosensitive molecules/biomolecules. The change on phase separation behavior can also enhance the partition of solutes, which makes the addition of small amounts of ILs a simple and effective strategy to improve the extraction and purification yields. First, in order to find biphasic regions for CCM partition studies at mild conditions, the phase diagrams of all Pluronic F68/buffer + ILs-based ATPMS were determined (Fig. 3).

As shown in Fig. 3, the use of cholinium ILs as adjuvants favored the formation of ATPMS, leading to a decrease of $T_{\mathrm{CP}}$ and an increase of the biphasic region. The influence of cholinium-based ILs is very dependent of the anion nature, decreasing the $T_{\mathrm{CP}}$ as the IL anion relative hydrophobicity increases, i.e.: $[\mathrm{Hex}]^{-}>[\mathrm{But}]^{-}>[\mathrm{Pro}]^{-}>[\mathrm{Ac}]^{-}>\mathrm{Cl}^{-}$. The formation of IL-based ATPMS results from a complex competition between the ILs and amphiphilic copolymers for water molecules, as well by the existence of specific interactions between the coexisting phase-forming components [37]. Salts and ILs can also influence the water structure according to their hydration (salting-in and salting-out) aptitudes [38-40].

The results shown in Fig. 3 seem to indicate that the hydrophobic interactions between PMs-based Pluronic F68 and hydrophobic portion of IL anionic alkyl chain are predominant for the $T_{\mathrm{CP}}$ decrease. When increasing the IL anion alkyl chain length, the relative hydrophobicity of IL also increases, consequently strengthening hydrophobic type interactions with the hydrophobic portion of micelles [41]. This effect can be confirmed by the significant increase of the biphasic region with $[\mathrm{Ch}][\mathrm{Hex}]$ and $[\mathrm{Ch}][\mathrm{But}]$ as adjuvants. It is likely that these ILs interact more easily with the PMs because of their higher relative hydrophobicity. Parmar et al. [42] confirmed that the presence of 


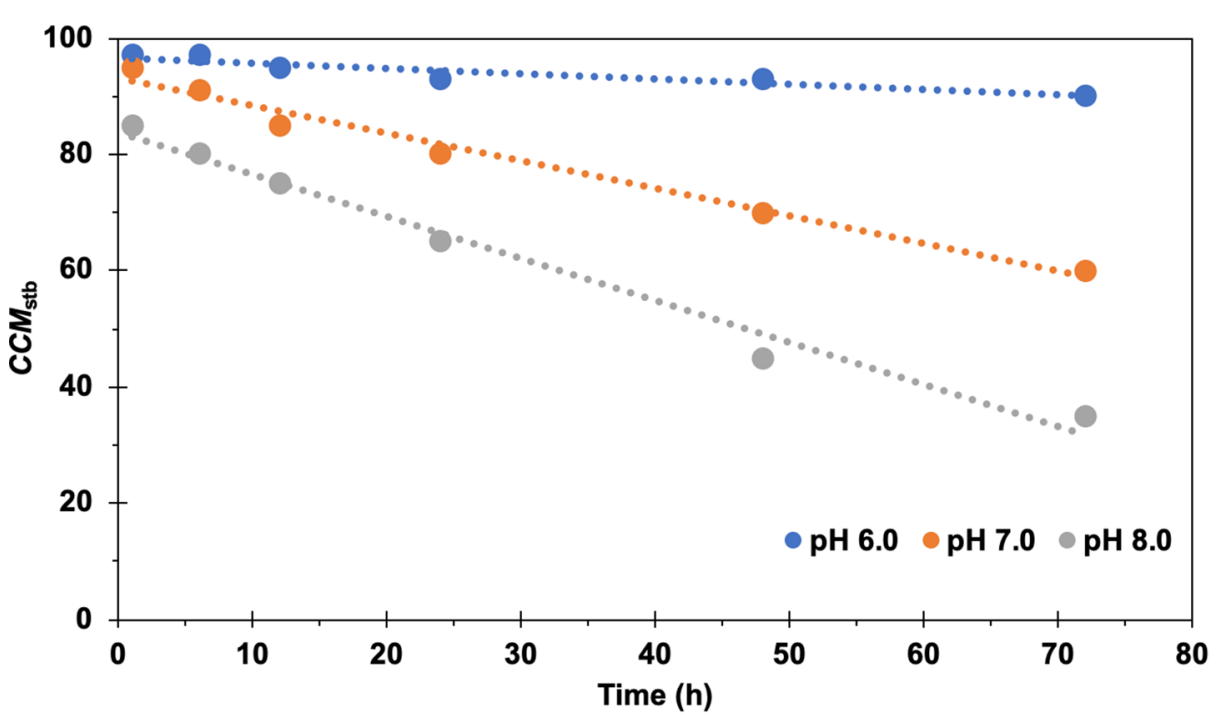

(a)

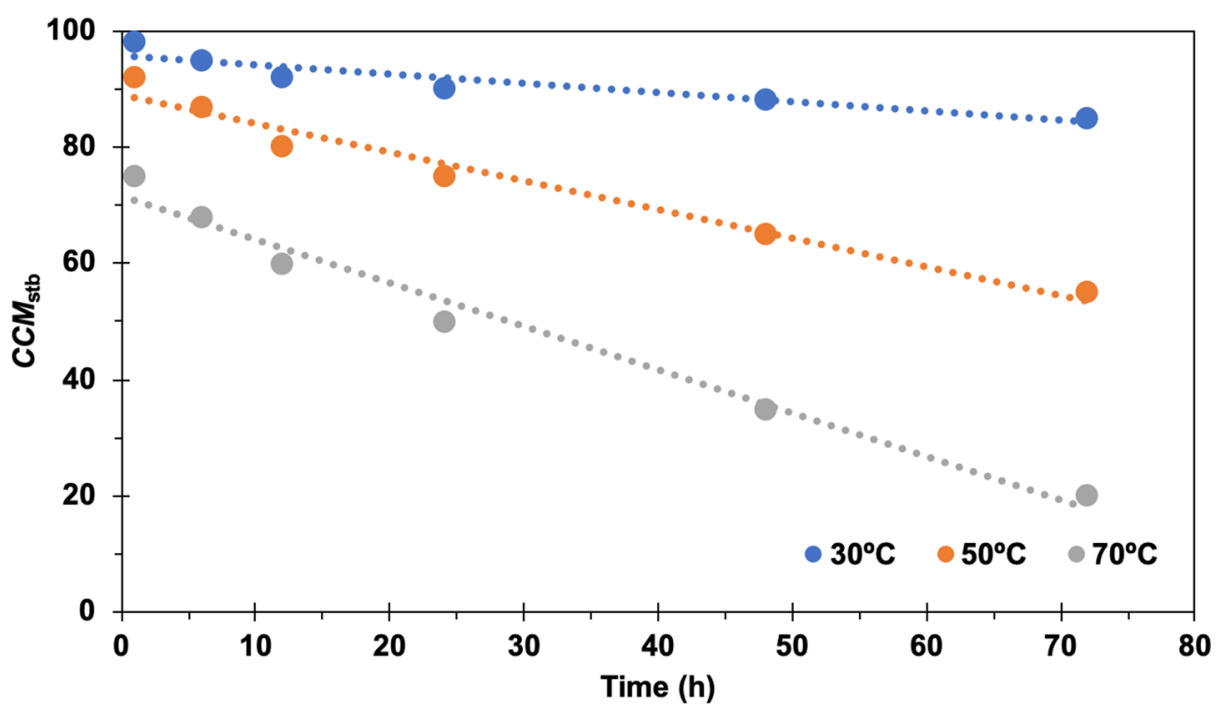

(b)

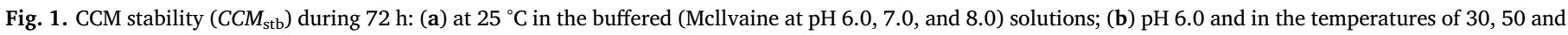
$70{ }^{\circ} \mathrm{C}$. The respective errors correspond to the $95 \%$ confidence levels for three independents measurements, but error bars are smaller than the markers.

hydrophobic 1-alkyl-3-methyl imidazolium tetrafluoroborates ( $\left[\mathrm{C}_{n} \mathrm{mim}\right]\left[\mathrm{BF}_{4}\right], n=4,6$, and 8 ) modify the shape and size of the amphiphilic copolymer Pluronic P103 (composed of $\mathrm{PEO}_{17} \mathrm{PPO}_{60^{-}}$ $\mathrm{PEO}_{17}$ ), promoting the formation of mixed micelles.

On the other hand, concerning the dehydration of $\mathrm{PEO}_{x}-\mathrm{PPO}_{y}-\mathrm{PEO}_{x}$ copolymer by adding ILs to aqueous solution, a recent study on the critical micellization temperature of Pluronic F108 aqueous solutions showed that the addition of cholinium bitartrate ([Ch] $[\mathrm{Bit}])$ and cholinium dihydrogen citrate ([Ch] [DHCit]) are more prone to dehydrate the copolymer than $[\mathrm{Ch}][\mathrm{Ac}]$ and $[\mathrm{Ch}] \mathrm{Cl}$ (with strong tendency of their ions to be hydrated) [43]. Despite the lower abilities of [Ch][Ac] and [Ch] Cl to form ATPMS, in comparison with the other cholinium ILs (Fig. 3), those ILs enlarged the biphasic region in comparison with the system without ionic additives (Pluronic F68 + Mcllvaine buffer). $[\mathrm{Ch}] \mathrm{Cl}$ and $[\mathrm{Ch}][\mathrm{Ac}]$ ions compete for water molecules around PEO chains of amphiphilic copolymers, increasing the micelle-micelle interactions and decreasing the $T_{\mathrm{CP}}$ (enlargement of the two-phase region) $[5,8]$. Our results are in agreement with findings of Teixeira-Pinto et al. [16], that observed a reduction of $T_{\mathrm{CP}}$ in $\mathrm{C}_{10} \mathrm{E}_{4}$ nonionic surfactant aqueous solutions + salts $\left(\mathrm{SO}_{4}{ }^{2-}>\mathrm{Cl}^{-}>\mathrm{NO}_{3}{ }^{-}>\mathrm{I}^{-}\right)$, and Silva et al. [8] that studied cholinium-based ILs + Pluronic L35 (composed of $\mathrm{PEO}_{11}-\mathrm{PPO}_{16}-\mathrm{PEO}_{11}$ ) ATPMS, observing an increase of the biphasic region as a function of the nature of the IL anion $\left([\mathrm{DHP}]^{-}>[\mathrm{Bit}]^{-}>[\mathrm{DHCit}]^{-}>[\mathrm{Bic}]^{-}>[\mathrm{Ac}]^{-}>\mathrm{Cl}^{-}\right)$.

\subsection{Partition of pure commercial CCM using Pluronic F68 + ILs ATPMS}

Considering stability and ATPMS phase diagrams results, the partition of commercial CCM was performed at low temperatures $(20<\mathrm{T}$ $\left({ }^{\circ} \mathrm{C}\right)<30$ ), short incubation time $(3 \mathrm{~h})$, and low concentrated Pluronic F68 + ILs aqueous solutions. In order to infer the effect of Pluronic F68 in the partition of CCM, ATPMS composed with two distinct polymer concentrations (i.e., 1.0 and $5.0 \mathrm{wt} \%$ ) were prepared, and mixed with different IL concentrations at mild temperatures (i.e., from 20 to $30^{\circ} \mathrm{C}$ ), as detailed in Table 2. CCM recovery in the PMs-rich phase $\left(R E C_{\text {Rich }}\right)$ and CCM partition coefficients $\left(K_{\mathrm{CCM}}\right)$ values are depicted in Fig. $4 \mathrm{a}$ and $4 \mathrm{~b}$, respectively. In order to guarantee equivalent tie-lines and micelles concentration $\left(\phi_{c}\right)$ in the PMs-rich phase in the presence of ILs, the binodal curves were experimentally obtained in the same region (Fig. 4c). Note that mass balances of CCM $(M B)$ were determined for all 


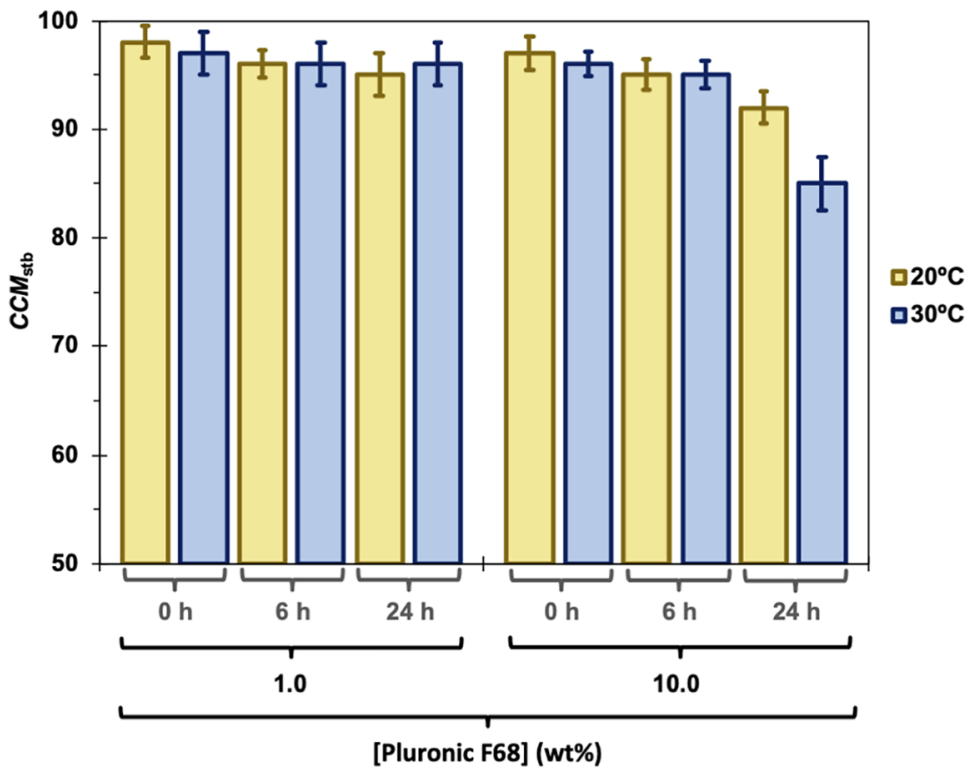

(a)

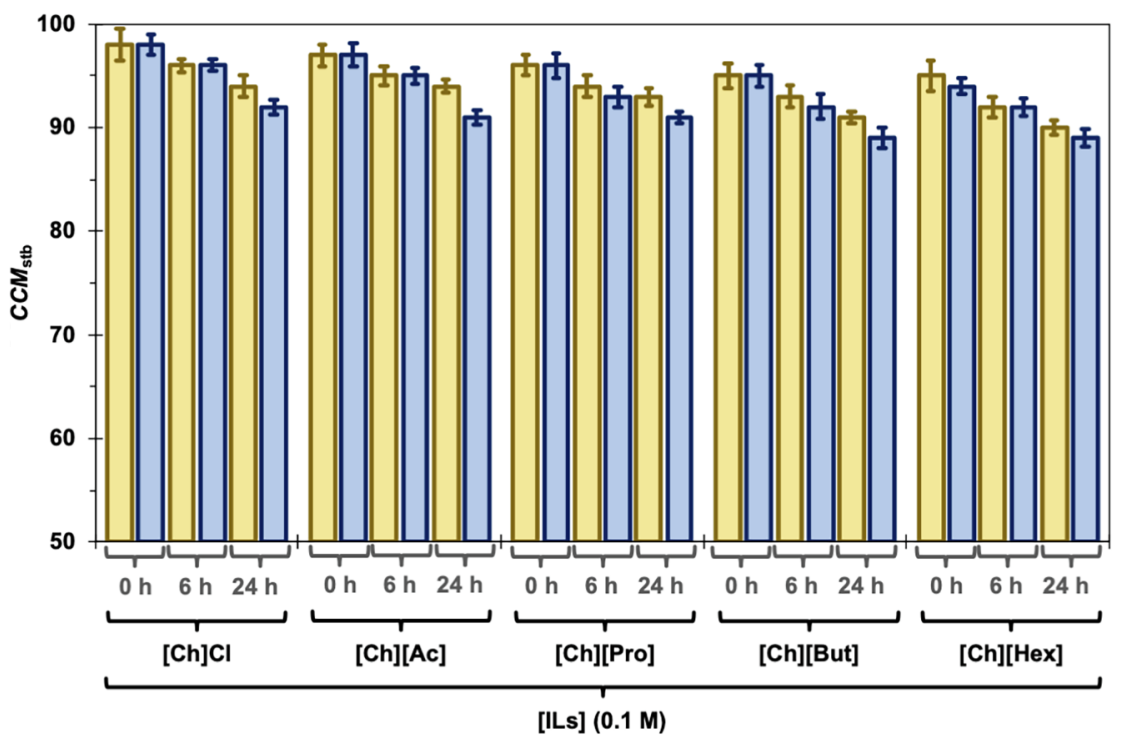

$\square 20^{\circ} \mathrm{C}$

$\square 30^{\circ} \mathrm{C}$

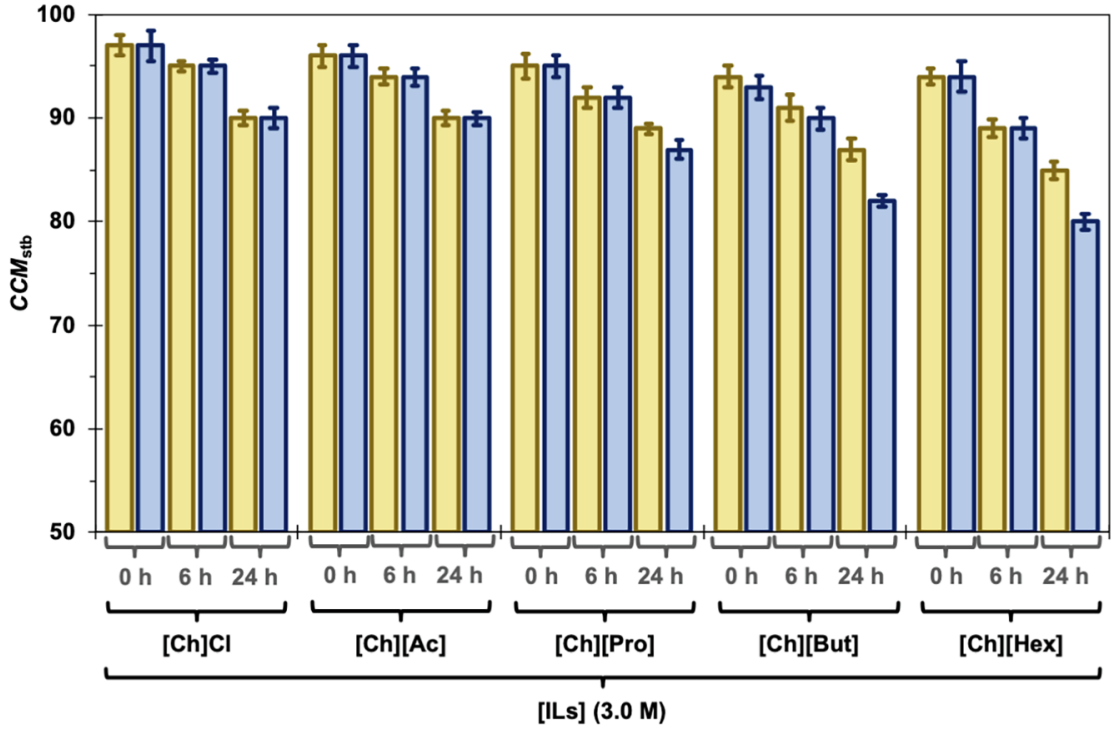

(c) 
Fig. 2. CCM stability $\left(C C M_{\text {stb }}\right.$ ) during $24 \mathrm{~h}$ (at 20 and $30{ }^{\circ} \mathrm{C}$ ) in the buffered (Mcllvaine at pH 6.0) solutions of: (a) Pluronic F68 (at 1.0 and $10.0 \mathrm{wt} \%$ ); (b) $1.0 \mathrm{M}$ and (c) $3.0 \mathrm{M}$ of the ionic liquids (ILs) $[\mathrm{Ch}] \mathrm{Cl},[\mathrm{Ch}][\mathrm{Ac}],[\mathrm{Ch}][\mathrm{Pro}]$, [Ch] [But], and $[\mathrm{Ch}][\mathrm{Hex}]$. The respective errors correspond to the $95 \%$ confidence levels for three independents measurements.

assays and found to be approximately $100 \%$ (data not shown).

Fig. $4 a$ and $4 b$ show that, independently of the Pluronic F68 concentration, $K_{\mathrm{CCM}}$ (in PMs-rich phase) increases with the increase of the IL anion alkyl chain length. CCM was preferentially partitioned in the PMs-rich phase, with $R E C_{\text {Rich }}$ (from 45 to $88 \%$ ) and $K_{\mathrm{CCM}}$ (from 3.5 to 22). ATPMS containing $0.70 \mathrm{M}$ of [Ch][But] and $0.60 \mathrm{M}$ of $[\mathrm{Ch}][\mathrm{Hex}]$ exhibited the highest $K_{\mathrm{CCM}}$, respectively, $15<K_{\mathrm{CCM}}<22$ (at $1.0 \mathrm{wt}$ $\%$ Pluronic F68) and $12<K_{\mathrm{CCM}}<16$ (at $5.0 \mathrm{wt} \%$ Pluronic F68). Since CCM is a hydrophobic compound, its preferential partition to the more hydrophobic phase (i.e., PMs-rich phase) is probably a result of favorable hydrophobic interactions. The Pluronic F68 is a triblock copolymer composed of $\mathrm{PEO}_{76}-\mathrm{PPO}_{29}-\mathrm{PEO}_{76}$ and, therefore, the hydrophobic PPO block must interact with the CCM molecules through hydrophobic interactions, favoring CCM migration to the PMs-rich phase. Letchford et al. [44] demonstrated that the amount of hydrophobic drugs (i.e., indomethacin, plumbagin, paclitaxel, etoposide, including CCM) solubilized in methoxy poly(ethylene glycol)-polycaprolactone (MePEG-b-PCL) micelles is directly related to the length of the hydrophobic block (PCL), resulting in higher drug loading in micelles with longer hydrophobic block lengths. The presence of ions affected not only ATPMS equilibria but also the solutes' partition, i.e. electrolyte solutions can affect their solubility in the coexisting phases $[6,8,45]$. It is evident that with the addition of more hydrophobic ILs ([Ch] $[\mathrm{Hex}]>[\mathrm{Ch}][\mathrm{But}]>[\mathrm{Ch}][\mathrm{Pro}]>[\mathrm{Ch}][\mathrm{Ac}] \approx[\mathrm{Ch}] \mathrm{Cl})$, a more hydrophobic environment is created in the micelle-rich phase, increasing CCM partition.

Fig. $4 \mathrm{c}$ shows that as the temperature increases, from $20{ }^{\circ} \mathrm{C}\left(\phi_{\mathrm{c}} \approx\right.$ $7.0 \mathrm{wt} \%)$ to $25{ }^{\circ} \mathrm{C}\left(\phi_{\mathrm{c}} \approx 8.5 \mathrm{wt} \%\right)$, the $K_{\mathrm{CCM}}$ into the PMs-rich phase is increased for both Pluronic F68 concentrations. In this case, with the temperature increase, there is an increase of excluded-volume effect (EV) $[12,34,45]$, as shown by high $\phi_{\mathrm{c}}$ values in the PMs-rich phase, which can explain the difference between the $K_{\mathrm{CCM}}$ values obtained.

Fig. $4 \mathrm{a}$ and $4 \mathrm{~b}$ showed that the decrease of Pluronic F68 concentration favor the CCM in the PMs-rich phase, i.e., $K_{\mathrm{CCM}}$ at $1 \mathrm{wt} \%$ Pluronic F68 $>K_{\mathrm{CCM}}$ at $5 \mathrm{wt} \%$ Pluronic F68. In order to understand if other effects are affecting $K_{\mathrm{CCM}}$, the $\mathrm{pH} /$ conductivity values of the PMsrich and -poor phases were analyzed (Fig. 5). It was observed that the difference in the conductivity $(\sigma)$ of both coexisting phases for the ATPMS containing $1.0 \mathrm{wt} \%$ ( $\sigma_{\mathrm{PMs}-\text { poor phase }}>>>\sigma_{\mathrm{PMs}-\text { rich }}$ phase,
Fig. 5a) is higher than for the ATPMS containing $5.0 \mathrm{wt} \%$ of Pluronic

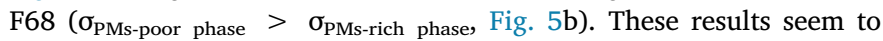
indicate that repulsive electrostatic interactions are enhancing the $K_{\mathrm{CCM}}$ towards the PMs-rich phase, in particular when used [Ch] Cl and [Ch] [Ac] as adjuvants. On the other hand, the $\sigma$ values of the PMs-rich phase increased with the increase of the IL anion alkyl chain length (namely, $[\mathrm{Ch}][$ Pro $]<[\mathrm{Ch}][$ But $]<[\mathrm{Ch}][\mathrm{Hex}]$ ), confirming higher incorporation rates of the more hydrophobic ILs in the micelle-rich phase. Recent experimental data of our group corroborate this phenomenon (unpublished data), in which an increase of the hydrodynamic diameter $\left(D_{\mathrm{H}}\right)$ of micelles (with Pluronic L35) in the presence of [Ch][But] and $[\mathrm{Ch}][\mathrm{Hex}]$ is observed, i.e. ILs that interact more effectively with copolymer molecules tend to form mixed micelles. In these systems, as the difference in $\sigma$ tends to decrease, the effect of $K_{\mathrm{CCM}}$ is mostly dominated by the aptitude of the CCM to promote hydrophobic interactions with the PMs (as discussed above).

\subsection{Purification of CCM from crude extract of Curcuma longa $L$.}

After the partition studies using pure commercial CCM, the two ATPMS with the highest $K_{\mathrm{CCM}}$ and $R E C_{\text {Rich }}$ values were selected to purify CCM from a real matrix. The recovery of CCM from crude samples (powdered material dried from $C$. longa L.) using the ATPMS composed of Pluronic F68 (1.0 wt\%) + [Ch][But] $(0.70 \mathrm{M})$ and Pluronic F68 $(1.0 \mathrm{wt} \%)+[\mathrm{Ch}][\mathrm{Hex}](0.60 \mathrm{M})$ were performed at $25{ }^{\circ} \mathrm{C}$, and the respective partition and purification parameters were determined (Table 3 ).

Both ATPMS were very effective in recovering CCM from crude samples of $C$. longa $\mathrm{L}$., as shown by high $R E C_{\text {Rich }}$ yields $(88 \pm 1.1 \%$ in the system with [Ch][But] and $92 \pm 1.3 \%$ with [Ch][Hex]). Interestingly, even when extracting CCM from a more complex matrix, the ability of both ATPMS to partition the CCM into PMs-rich phase was enhanced. Slight increases of the $K_{\mathrm{CCM}}$ from the crude sample $\left(K_{\mathrm{CCM}}\right.$, with $0.60 \mathrm{M}{ }_{[\mathrm{Ch}][\mathrm{Hex}]}=25>K_{\mathrm{CCM}}$, with $\left.0.70 \mathrm{M}{ }_{[\mathrm{Ch}][\mathrm{But}]}=20\right)$ in comparison to those obtained with pure CCM $\left(K_{\mathrm{CCM}}\right.$, with $0.60 \mathrm{M}$ [Ch] $[\mathrm{Hex}]=22>K_{\mathrm{CCM}}$, with $\left.0.70 \mathrm{M}[\mathrm{Ch}][\mathrm{But}]=18\right)$ were observed. It seems that the presence of substantial amounts of hydrophilic contaminants in the crude sample $(0.55 \mathrm{mg} / \mathrm{mL})$ is repelling the CCM molecules from the PMs-poor phase.

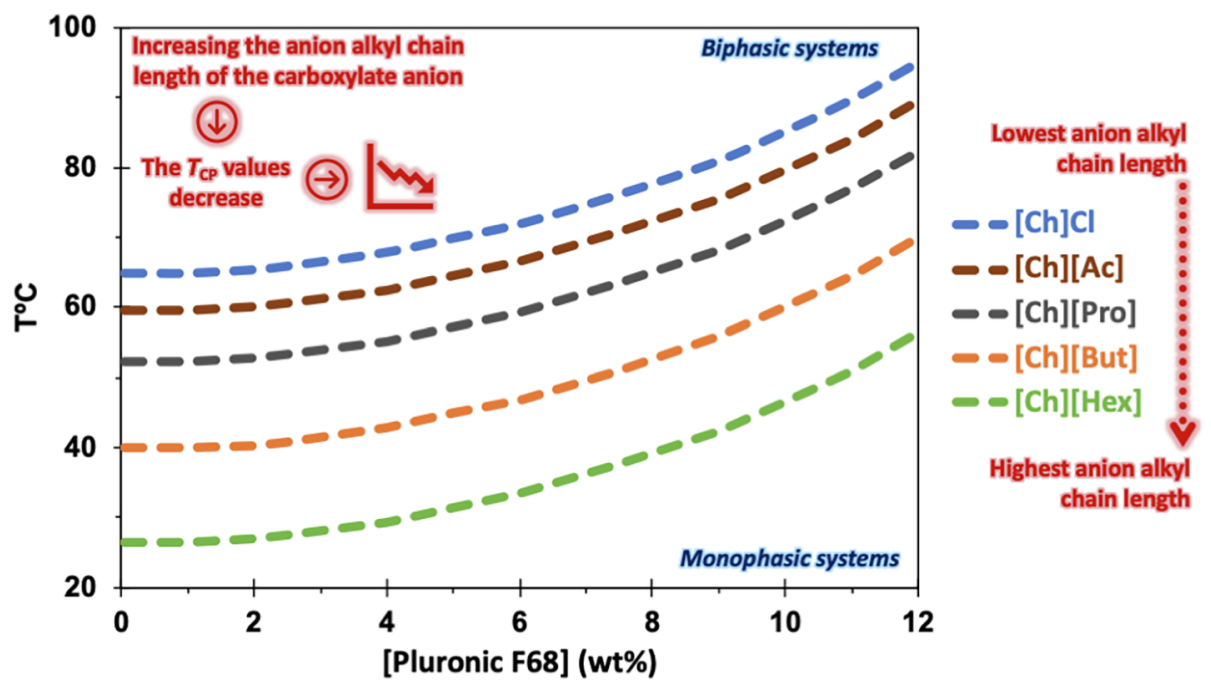

Fig. 3. Binodal curves obtained by cloud point $\left(T_{\mathrm{CP}}\right)$ method for aqueous two-phase micellar systems (ATPMS) composed of Pluronic F68 and Mcllvaine buffer (pH $6.0)+0.5 \mathrm{M}$ of ionic liquids (ILs), namely: [Ch]Cl (blue); [Ch][Ac] (brown); [Ch] [Pro] (gray); [Ch] [But] (orange); and [Ch][Hex] (green). 


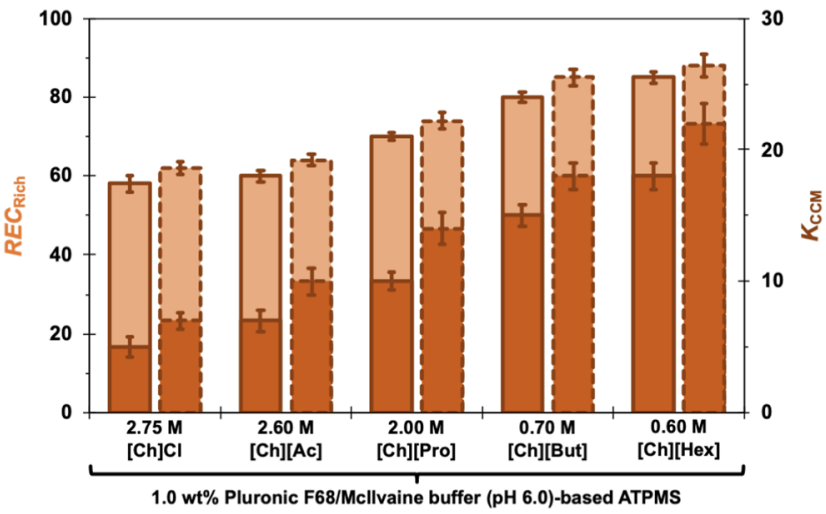

(a)

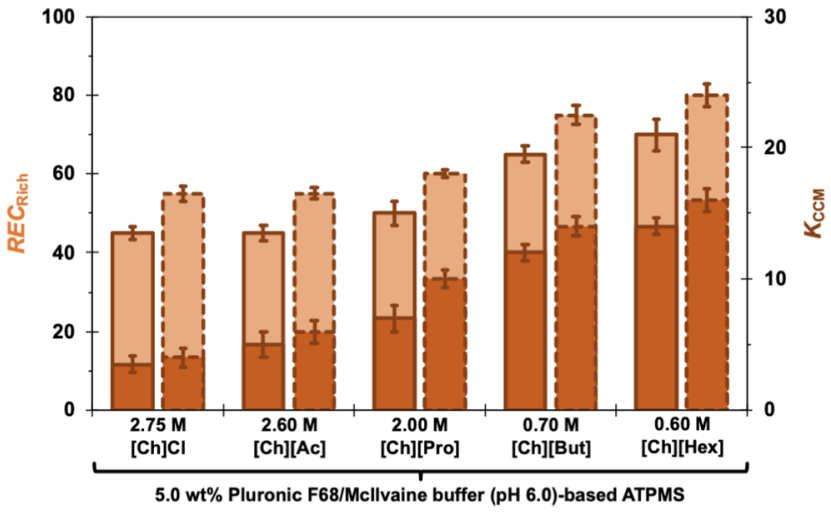

(b)

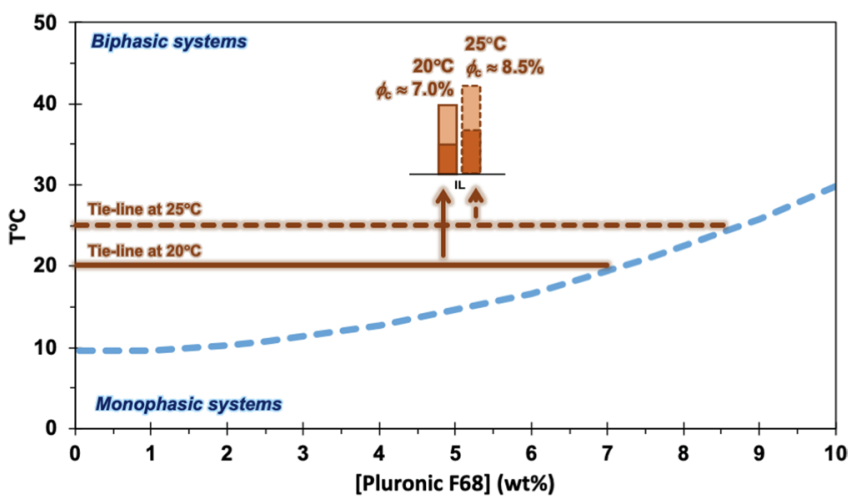

(c)

Fig. 4. Partition of curcumin (CCM) in aqueous two-phase micellar systems (ATPMS) composed of (a) $1.0 \mathrm{wt} \%$, and (b) 5.0 wt $\%$ Pluronic F68 and different ionic liquids (ILs), namely: $2.75 \mathrm{M} \mathrm{[Ch]Cl;} 2.60 \mathrm{M}$ [Ch][Ac]; $2.00 \mathrm{M}$ [Ch][Pro]; $0.70 \mathrm{M} \mathrm{[Ch][But];} \mathrm{and} 0.60 \mathrm{M}$ [Ch] [Hex] at $20^{\circ} \mathrm{C}$ (solid lines) and $25{ }^{\circ} \mathrm{C}$ (dashed lines).

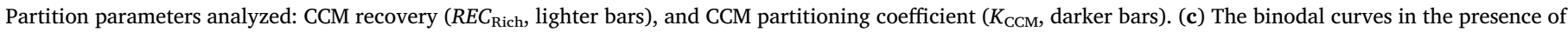
ILs were experimentally obtained in the same region. The $\phi_{\mathrm{c}}$ corresponds to the Pluronic F68 concentration in the polymeric micelles (PMs)-rich phase, in this case $\phi_{\mathrm{c}}$ values at $20{ }^{\circ} \mathrm{C}$ and $25{ }^{\circ} \mathrm{C}$ were estimated in 7.0 and $8.5 \mathrm{wt} \%$, respectively. The respective errors correspond to the $95 \%$ confidence levels for three independents measurements.

In addition to the excellent partition abilities, both ATPMS were also very efficient in purifying CCM from the protein-based contaminants, as confirmed by high selectivity values $(S$ with $0.60 \mathrm{M}$ [Ch] $\left.[\mathrm{Hex}]=30 \pm 0.75>S_{\text {with } 0.70 \mathrm{M}[\mathrm{Ch}][\mathrm{But}]}=25 \pm 0.45\right)$ and purification yields $\left(P_{\mathrm{F} \text {, with } 0.60 \mathrm{M}[\mathrm{Ch}][\mathrm{Hex}]}=15 \pm 0.65>P_{\mathrm{F} \text {, with } 0.70 \mathrm{M}}\right.$ $[\mathrm{Ch}][$ But $]=12 \pm 0.50)$. Because of the more hydrophilic character of the contaminant proteins, these are preferentially partitioned into the PMs-poor phase, while the hydrophobic CCM is concentrated in the more hydrophobic environment.

CCM is a major active component of the Indian spice turmeric ( $C$. longa). In this sense, commercially available crude CCM contains significant amounts of structurally similar compounds, known as curcuminoids. This class of bioactive compounds is mostly comprised by three fundamental components, namely, CCM $(\approx 75$ wt $\%)$, demethoxycurcumin (DMC, $\approx 10-25 \mathrm{wt} \%$ ), and bisdemethoxycurcumin (BDMC, $\approx 5 \mathrm{wt} \%$ ), included in the diferuloylmethane group of phenolic compounds $[26,46]$. The three major curcuminoids are structurally very similar, distinguished only by (the presence/absence of) a methoxy functional group on each of the aromatic rings [18]. Therefore, more than the removal of hydrophilic contaminants, it is the selective purification of similar curcuminoids the biggest challenge. To confirm if these ATPMS are efficient in the selective purification of CCM from the other major curcuminoids, a careful analysis (by HPLC) of curcuminoids content of the crude sample ( $C$. longa L.) before and after the purification using ATPMS was carried out. Initially, the crude sample was composed of $70 \mathrm{wt} \%$ CCM, $12 \mathrm{wt} \%$ DMC, and $5.5 \mathrm{wt} \%$ of BDMC. After the purification step, the PMs-rich phase included $77 \mathrm{wt} \% \mathrm{CCM}$ and $18 \mathrm{wt} \% \mathrm{DMC}$, with no detectable concentration of BDMC. Although selective separation of curcuminoids was not the objective of this work, these preliminary results are very promising, demonstrating that at least one of the major curcuminoids was fully removed (i.e., BMDC) by using a single ATPMS extraction step, as illustrated in Fig. 6. In further studies, we will design and propose additional strategies to obtain selective separation of individual curcuminoids using single or integrated ATPMS-based platforms.

Regarding the purification of curcuminoids, several promising downstream processing platforms have been proposed in the last 5 years $[18,26,46-50]$. Despite of good CCM recovery yields and purification factors, most previous studies applied very energetic operations, like subcritical solvent extraction [47], cooling crystallization [46], ultrasound-assisted methods [49,50] or combining multiple, timeconsuming and laborious stages $[18,26]$. The high recovery/purification performances together with the milder processing conditions (mild temperatures and VOCs-free) make these Pluronic F68/water + ILsbased ATPMS very interesting platforms for the purification of CCM from C. longa L., at least, to replace some of the more energy-consuming and environmentally heavier current downstream units.

\section{Conclusions}

These results demonstrated the importance of a proper IL-based ATPMS design, namely, by increasing the relative hydrophobicity of the IL anion, to increase the partition of hydrophobic molecules (e.g., curcuminoids, flavonoids, among other bioactive molecules) into the PMsrich phase. These ATPMS required low concentrations of copolymer and ILs (i.e., $1.0 \mathrm{wt} \%$ and $0.70 \mathrm{M}$ for [Ch][But] and $0.60 \mathrm{M}$ for [Ch][Hex], 


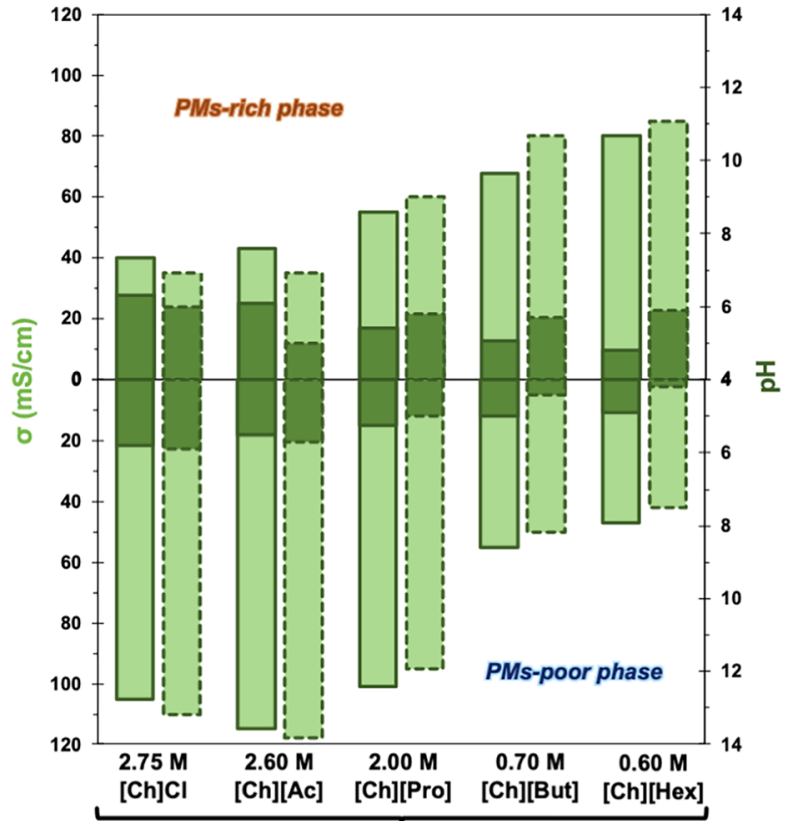

1.0 wt\% Pluronic F68/Mcllvaine buffer (pH 6.0)-based ATPMS

(a)

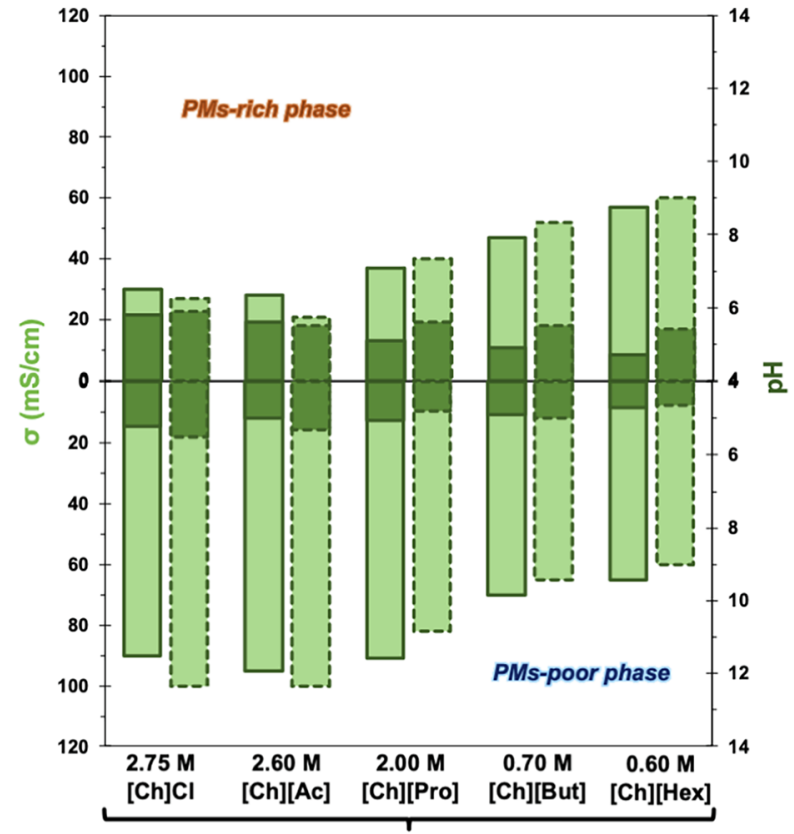

5.0 wt\% Pluronic F68/Mcllvaine buffer (pH 6.0)-based ATPMS

(b)

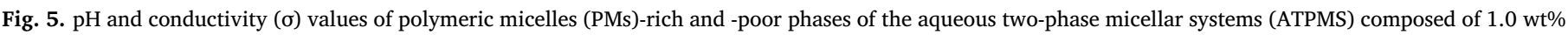

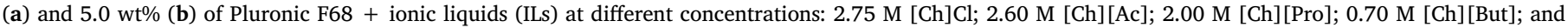
$0.60 \mathrm{M}[\mathrm{Ch}][\mathrm{Hex}]$ at $20^{\circ} \mathrm{C}$ (solid lines) and $25^{\circ} \mathrm{C}$ (dashed lines).

Table 3

Experimental results of curcumin partition ( $K_{\mathrm{CCM}}$ and $R E C_{\text {Rich }}$ ), purification factor $\left(P_{\mathrm{F}}\right)$, and selectivity $(S)$ from crude sample of $C$. longa L. using aqueous two-phase micellar systems (ATPMS) composed of $1 \mathrm{wt} \%$ Pluronic F68 + ionic liquids (ILs) at $25{ }^{\circ} \mathrm{C}$ and $\mathrm{pH} 6.0$. The respective errors correspond to the $95 \%$ confidence levels for three independents measurements.

\begin{tabular}{lll}
\hline \multirow{2}{*}{ Parameters } & \multicolumn{2}{l}{ Pluronic F68 $(1 \mathrm{wt} \%)+$ ILs-based ATPMS } \\
\cline { 2 - 3 } & {$[\mathrm{Ch}][\mathrm{But}](0.70 \mathrm{M})$} & {$[\mathrm{Ch}][\mathrm{Hex}](0.60 \mathrm{M})$} \\
\hline $\boldsymbol{K}_{\text {CCM }}$ & $20 \pm 0.04$ & $25 \pm 0.05$ \\
$\boldsymbol{R E} \boldsymbol{C}_{\text {Rich }}$ & $88 \pm 1.1 \%$ & $92 \pm 1.3 \%$ \\
$\boldsymbol{P}_{\mathbf{F}}$ & $12 \pm 0.50$ & $15 \pm 0.65$ \\
$\boldsymbol{S}$ & $25 \pm 0.45$ & $30 \pm 0.75$ \\
\hline
\end{tabular}

respectively) to form biphasic regimes, as well as to guarantee high CCM recovery yields. The partition/purification of CCM results confirm the potential of IL-based ATPMS as a simple, mild, safe and environmentally friendly platform for the replacement of common VOCsbased extraction methods and chromatographic-based purification processes. This work demonstrated that Pluronic F68/buffer + ILsbased ATPMS are feasible options for the purification of bioactive compounds from complex media by a selective removal of hydrophobic molecules from the more hydrophilic protein-based contaminants. In addition to the use of ATPMS as extraction platforms, these systems are also promising to encapsulate hydrophobic molecules/biomolecules within nanostructures (i.e., polymeric micelles - PMs) and to develop novel drug delivery systems (DDS).

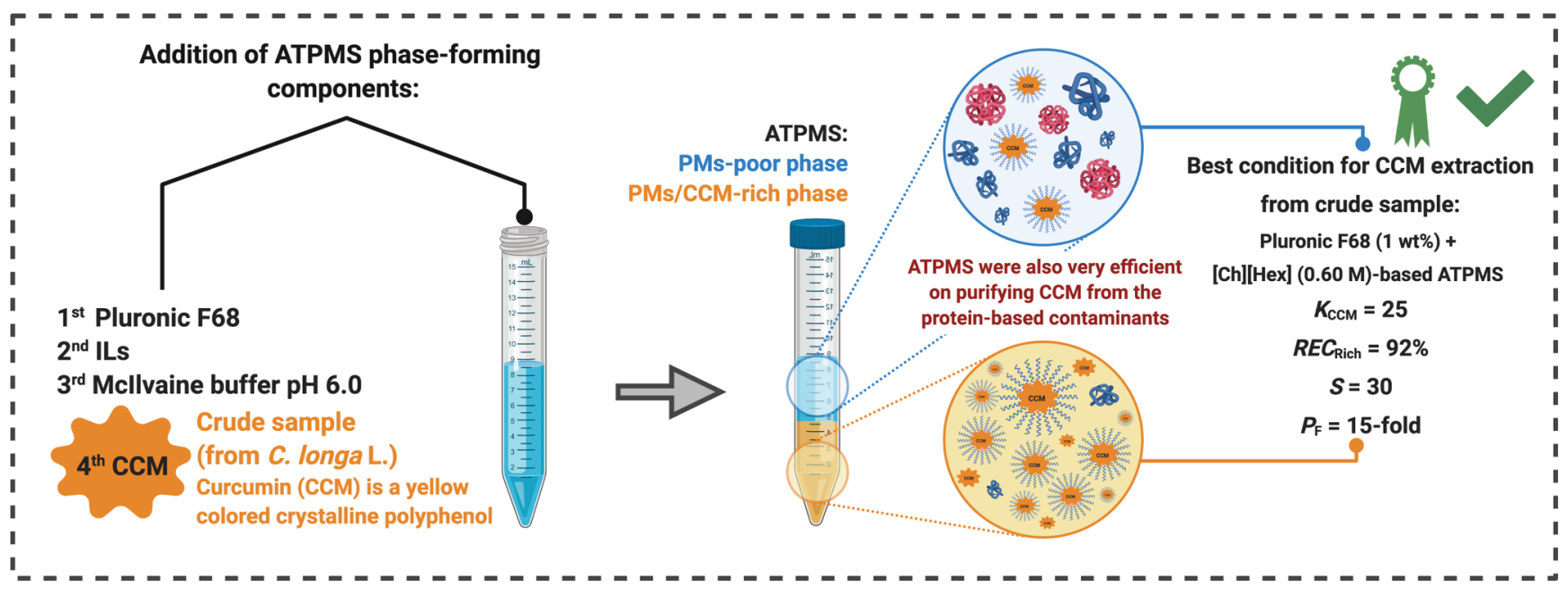

Fig. 6. A schematic representation of the separation process for the partition/purification of curcumin (CCM) using aqueous two-phase micellar systems (ATPMS). Experimental results of CCM partition $\left(K_{\mathrm{CCM}}\right.$ and $\left.R E C_{\text {Rich }}\right)$, purification factor $\left(P_{\mathrm{F}}\right)$, and selectivity $(S)$ from crude sample of $C$. longa L. using the best ATPMS (1 wt $\%$ Pluronic F68 + 0.60 M [Ch] [Hex] at $25^{\circ} \mathrm{C}$ and $\mathrm{pH} 6.0$ ). PMs correspond to polymeric micelles. 


\section{Declaration of Competing Interest}

The authors declare that they have no known competing financial interests or personal relationships that could have appeared to influence the work reported in this paper.

\section{Acknowledgements}

This study was funded by the Coordination for Higher Level Graduate Improvements (CAPES/Brazil, finance code 001), National Council for Scientific and Technological Development (CNPq/Brazil) and the State of São Paulo Research Foundation (FAPESP/Brazil, processes \#2014/16424-7, \#2017/10789-1, \#2018/10799-0, \#2018/ 05111-9; \#2019/05624-9, and \#2019/08549-8). A.M. Lopes and J.F.B. Pereira are grateful for the language revision of native speaker H.S. Pacheco Neto.

\section{References}

[1] M.G. Freire, A.F.M. Cláudio, J.M.M. Araújo, J.A.P. Coutinho, I.M. Marrucho, J.N.C. Lopes, L.P.N. Rebelo, Aqueous biphasic systems: a boost brought about by using ionic liquids, Chem. Soc. Rev. 41 (2012) 4966-4995, https://doi.org/10. 1039/c2cs35151j.

[2] F.A. Vicente, I.S. Cardoso, T.E. Sintra, J. Lemus, E.F. Marques, S.P.M. Ventura, J.A.P. Coutinho, Impact of surface active ionic liquids on the cloud points of nonionic surfactants and the formation of aqueous micellar two-phase systems, J. Phys. Chem. B 121 (2017) 8742-8755, https://doi.org/10.1021/acs.jpcb.7b02972.

[3] J.F.B. Pereira, L.P.N. Rebelo, R.D. Rogers, J.A.P. Coutinho, M.G. Freire, Combining ionic liquids and polyethylene glycols to boost the hydrophobic-hydrophilic range of aqueous biphasic systems, Phys. Chem. Chem. Phys. 15 (2013) 19580-19583, https://doi.org/10.1039/C3CP53701C.

[4] J.F.B. Pereira, Rudolf Deutschmann, Robin D. Rogers, On the hunt for more benign and biocompatible abs. in ionic-liquid-based aqueous biphasic systems: fundamentals and applications, Springer Berlin Heidelberg: Berlin, Heidelberg, 2016, pp. 247-284 10.1007/978-3-662-52875-4_11.

[5] F.A. Vicente, L.P. Malpiedi, F.A. Silva, A. Pessoa-Jr, J.A. Coutinho, S.P. Ventura, Design of novel aqueous micellar two-phase systems using ionic liquids as co-surfactants for the selective extraction of (bio)molecules, Sep. Purif. Technol. 135 (2014) 259-267, https://doi.org/10.1016/j.seppur.2014.06.045.

[6] M.V. Quental, M. Caban, M.M. Pereira, P. Stepnowski, J.A.P. Coutinho, M.G. Freire, Enhanced extraction of proteins using cholinium-based ionic liquids as phaseforming components of aqueous biphasic systems, Biotechnol. J. 10 (2015) 1457-1466, https://doi.org/10.1002/biot.201500003.

[7] G.D. Rodrigues, L.D.S. Teixeira, G.M.D. Ferreira, M.D.C.H. da Silva, L.H.M. da Silva, R.M.M. de Carvalho, Phase diagrams of aqueous two phase systems with organic salts and F68 triblock copolymer at different temperatures, J. Chem. Eng. Data 55 (2009) 1158-1165, https://doi.org/10.1021/je900581a.

[8] F.A. Silva, R.M. Carmo, A.P. Fernandes, M. Kholany, J.A. Coutinho, S.P. Ventura, Using ionic liquids to tune the performance of aqueous biphasic systems based on Pluronic L-35 for the purification of naringin and rutin, ACS Sustain, Chem. Eng. (2017) 6409-6419, https://doi.org/10.1021/acssuschemeng.7b00178.

[9] A. Pitto-Barry, N.P.E. Barry, Pluronic ${ }^{\circledast}$ block-copolymers in medicine: from chemical and biological versatility to rationalisation and clinical advances, Polym. Chem. 5 (2014) 3291-3297, https://doi.org/10.1039/C4PY00039K.

[10] D. Forciniti, Preparation of aqueous two-phase systems, Meth. Biotechnol. 11 (2000) 23-33, https://doi.org/10.1385/1-59259-028-4:23.

[11] A.V. Kabanov, E.V. Batrakova, V.Y. Alakhov, Pluronic block copolymers as novel polymer therapeutics for drug and gene delivery, J Control Release 82 (2002) 189-212, https://doi.org/10.1016/S0168-3659(02)00009-3.

[12] C.L. Liu, Y.J. Nikas, D. Blankschtein, Novel bioseparations using twophase aqueous micellar systems, Biotechnol. Bioeng. 52 (1996) 185-192, https://doi.org/10. 1002/(SICI)1097-0290(19961020)52:2 < 185::AID-BIT1 > 3.0.CO;2-M.

[13] R.D. Rogers, J. Zhang, Effects of increasing polymer hydrophobicity on distribution ratios of $\mathrm{TcO}_{4}{ }^{-}$in polyethylene/poly (propylene glycol)-based aqueous biphasic systems, J. Chromatogr. Biomed. Appl. 680 (1996) 231-236, https://doi.org/10. 1016/0378-4347(95)00389-4.

[14] J.W. Kwon, Y.K. Han, W.J. Lee, C.S. Cho, S.J. Paik, D.I. Cho, J.H. Lee, W.R. Wee, Biocompatibility of poloxamer hydrogel as an injectable intraocular lens: A pilot study, J. Cataract Refractive Surg. 31 (2005) 607-613, https://doi.org/10.1016/j. jcrs.2004.05.051.

[15] F.A. Hasmann, V.C. Santos, D.B. Gurpilhares, A. Pessoa-Junior, I.C. Roberto, Aqueous two-phase extraction using thermoseparating copolymer: a new system for phenolic compounds removal from hemicelullosic hydrolysate, J. Chem. Technol. Biotechnol. 83 (2008) 167-173, https://doi.org/10.1002/jctb.1779.

[16] R.G. Teixeira-Pinto, J.V. Molino, V.C. Santos-Ebinuma, A. Pessoa-Jr, S.R. Valentini, J.F.B. Pereira, A.M. Lopes, Effect of electrolytes as adjuvants in GFP and LPS partitioning on aqueous two-phase systems: 2. Nonionic micellar systems, Sep. Purif. Technol 210 (2019) 69-79, https://doi.org/10.1016/j.seppur.2018.04.090.

[17] N. Yeredla, N. Kojima, Y. Yang, S. Takayama, M. Kanapathipillai, Aqueous twophase system assisted self-assembled PLGA microparticles, Sci. Rep-UK 6
(2016) 1-8.

[18] C. Heffernan, M. Ukrainczyk, R.K. Gamidi, B.K. Hodnett, Å.C. Rasmuson, Extraction and purification of curcuminoids from crude curcumin by a combination of crystallization and chromatography, Org. Process Res. Dev. 21 (2017) 821-826, https://doi.org/10.1021/acs.oprd.6b00347.

[19] R.K. Maheshwari, A.K. Singh, J. Gaddipati, R.C. Srimal, Multiple biological activities of curcumin: a short review, Life Sci. 78 (2006) 2081-2087, https://doi.org/ 10.1016/j.lfs.2005.12.007.

[20] G. Grynkiewicz, P. Ślifirski, Curcumin and curcuminoids in quest for medicinal status, Acta Biochim. Polym. 59 (2012) 201-212, https://doi.org/10.18388/abp. 2012_2139.

[21] M. Magro, R. Campos, D. Baratella, M.I. Ferreira, E. Bonaiuto, V. Corraducci, F. Vianello, Magnetic purification of curcumin from Curcuma longa rhizome by novel naked maghemite nanoparticles, J. Agric. Food Chem. 63 (2015) 912-920, https://doi.org/10.1021/jf504624u.

[22] F. Bucar, A. Wube, M. Schmid, Natural product isolation - how to get from biological material to pure compounds, Nat. Prod. Rep. 30 (2013) 525-545, https:// doi.org/10.1039/C3NP20106F.

[23] G. Joana Gil-Chávez, J.A. Villa, J. Fernando Ayala-Zavala, J. Basilio Heredia, D. Sepulveda, E.M. Yahia, G.A. González-Aguilar, Technologies for extraction and production of bioactive compounds to be used as nutraceuticals and food ingredients: An overview, Compr. Rev. Food Sci. Food Saf. 12 (2013) 5-23, https:// doi.org/10.1111/1541-4337.12005.

[24] K. Grodowska, A. Parczewski, Organic solvents in the pharmaceutical industry, Acta Pol. Pharm. 67 (2010) 3-12.

[25] J.L. Shamshina, P. Berton, H. Wang, X. Zhou, G. Gurau, R.D. Rogers, Ionic liquids in pharmaceutical industry, Green Tech, Org. Synth. Med. Chem. (2018) 539-577, https://doi.org/10.1002/9781119288152.ch20.

[26] S.S. Patil, S. Bhasarkar, V.K. Rathod, Extraction of curcuminoids from Curcuma longa: comparative study between batch extraction and novel three phase partitioning, Prep. Biochem. Biotechnol. 49 (2019) 407-418, https://doi.org/10.1080/ 10826068.2019.1575859.

[27] N. Muhammad, M.I. Hossain, Z. Man, M. El-Harbawi, M.A. Bustam, Y.A. Noaman, N.B.M. Alitheen, M.K. Ng, G. Hefter, C.Y. Yin, Synthesis and physical properties of choline carboxylate ionic liquids, J. Chem. Eng. Data. 57 (2012) 2191-2196, https://doi.org/10.1021/je300086w.

[28] P.A. Albertsson, Partition of cell particles and macromolecules: separation and purification of biomolecules, cell organelles, membranes, and cells in aqueous polymer two-phase systems and their use in biochemical analysis and biotechnology, third ed., Wiley-Interscience, New York, Chichester, 1986, p. 346.

[29] T. Esatbeyoglu, P. Huebbe, I. Ernst, D. Chin, A.E. Wagner, G. Rimbach, Curcumin from molecule to biological function, Angew. Chem. Int. 51 (2012) 5308-5332, https://doi.org/10.1002/anie.201107724.

[30] Y.J. Wang, M.H. Pan, A.L. Cheng, L.I. Lin, Y.S. Ho, C.Y. Hsieh, J.K. Lin, Stability of curcumin in buffer solutions and characterization of its degradation products, J. Pharmaceut. Biomed. 15 (1997) 1867-1876, https://doi.org/10.1016/S07317085(96)02024-9.

[31] Y. Wang, Z. Lu, F. Lv, X. Bie, Study on microencapsulation of curcumin pigments by spray drying, Eur. Food Res. Technol. 229 (2009) 391-396, https://doi.org/10. 1007/s00217-009-1064-6.

[32] D. Suresh, H. Manjunatha, K. Srinivasan, Effect of heat processing of spices on the concentrations of their bioactive principles: Turmeric (Curcuma longa), red pepper (Capsicum annuum) and black pepper (Piper nigrum), J. Food Compos. Anal. 20 (2007) 346-351, https://doi.org/10.1016/j.jfca.2006.10.002.

[33] A. Magri, T. Pecorari, M.M. Pereira, E.M. Cilli, T.L. Greaves, J.F. Pereira, Enhancing the biocatalytic activity of L-Asparaginase using aqueous solutions of choliniumbased ionic liquids, ACS Sustain. Chem. Eng. 7 (2019) 19720-19731, https://doi. org/10.1021/acssuschemeng.9b04931.

[34] S.S. Sabo, A.M. Lopes, V.C. Santos-Ebinuma, C.O. Rangel-Yagui, R.P.S. Oliveira, Bacteriocin partitioning from a clarified fermentation broth of Lactobacillus plantarum ST16Pa in aqueous two-phase systems with sodium sulfate and choline-based salts as additives, Process Biochem. 66 (2018) 212-221, https://doi.org/10.1016/j. procbio.2017.11.018.

[35] A.M. Lopes, V.C. Santos-Ebinuma, A. Pessoa Jr., C.O. Rangel-Yagui, Influence of salts on the coexistence curve and protein partitioning in nonionic aqueous twophase micellar systems, Braz. J. Chem. Eng. 31 (2014) 1057-1064, https://doi.org/ 10.1590/0104-6632.20140314s00002677.

[36] L.S. Hao, P. Hu, Y.Q. Nan, Salt effect on the rheological properties of the aqueous mixed cationic and anionic surfactant systems, Colloids Surf. A 361 (2010) 187-195, https://doi.org/10.1016/j.colsurfa.2010.03.035.

[37] G. Ulloa, C. Coutens, M. Sánchez, J. Sineiro, A. Rodríguez, F.J. Deive, M.J. Núñez, Sodium salt effect on aqueous solutions containing Tween 20 and Triton X-102G, J. Chem. Thermodyn. 47 (2012) 62-67, https://doi.org/10.1016/j.jct.2011.09.021.

[38] F. Hofmeister, Zur lehre von der wirkung der salze. II. Archiv fur experimentelle, Pathologie und Pharmakologie 24 (1888) 247-260 (Translated In: W. Kunz, J. Henle, B.W. Ninha, About the science of the effect of salts: Franz Hofmeister's historical papers, Curr. Opin. Colloid Interface Sci. 9 (2004) 19-37). https://doi. org/10.1007/BF01838161.

[39] Y. Marcus, Effect of ions on the structure of water: structure making and breaking, Chem. Rev. 109 (2009) 1346-1370, https://doi.org/10.1021/cr8003828.

[40] K.D. Collins, M.W. Washabaugh, The Hofmeister effect and the behaviour of water at interfaces, Q. Rev. Biophys. 18 (1985) 323-422, https://doi.org/10.1017/ S0033583500005369.

[41] T. Sun, S. Gao, Q. Chen, X. Shen, Investigation on the interactions between hydrophobic anions of ionic liquids and Triton X-114 micelles in aqueous solutions, Colloids Surf. A 456 (2014) 18-25. 
[42] A. Parmar, V.K. Aswal, P. Bahadur, Interaction between the ionic liquids 1-alkyl-3methylimidazolium tetrafluoroborate and Pluronic ${ }^{\circledR}$ P103 in aqueous solution: a DLS, SANS and NMR study, Spectrochim. Acta. Part A 97 (2012) 37-143, https:// doi.org/10.1016/j.saa.2012.05.075.

[43] I. Khan, R. Umapathi, M.C. Neves, J.A.P. Coutinho, P. Venkatesu, Structural insights into the effect of cholinium-based ionic liquids on the critical micellization temperature of aqueous triblock copolymers, Phys. Chem. Chem. Phys. 18 (2016) 8342-8351, https://doi.org/10.1039/C5CP07079A.

[44] K. Letchford, R. Liggins, H. Burt, Solubilization of hydrophobic drugs by methoxy poly(ethylene glycol)-block-polycaprolactone diblock copolymer micelles: theoretical and experimental data and correlations, J. Pharm. Sci. 97 (2008) 1179-1190, https://doi.org/10.1002/jps.21037.

[45] A.M. Lopes, J.V.D. Molino, V.C. Santos-Ebinuma, A. Pessoa Jr, S.R. Valentini, J.F.B. Pereira, Effect of electrolytes as adjuvants in GFP and LPS partitioning on aqueous two-phase systems: 1. Polymer-polymer systems, Sep. Purif. Technol. 206 (2018) 39-49, https://doi.org/10.1016/j.seppur.2018.04.090.

[46] M. Ukrainczyk, B.K. Hodnett, Å.C. Rasmuson, Process parameters in the purification of curcumin by cooling crystallization, Org. Process Res. Dev. 20 (2016) 1593-1602, https://doi.org/10.1021/acs.oprd.6b00153.

[47] H.L. Kwon, M.S. Chung, Pilot-scale subcritical solvent extraction of curcuminoids from Curcuma longa L, Food chem. 185 (2015) 58-64, https://doi.org/10.1016/j. foodchem.2015.03.114.

[48] Y. Shu, M. Gao, X. Wang, R. Song, J. Lu, X. Chen, Separation of curcuminoids using ionic liquid based aqueous two-phase system coupled with in situ dispersive liquid - liquid microextraction, Talanta 149 (2016) 6-12, https://doi.org/10.1016/j talanta.2015.11.009.

[49] C. Kimthet, H. Wahyudiono, Kanda, M. Goto, Extraction of curcumin from Curcuma longa L. using ultrasound assisted supercritical carbon dioxide, In AIP Conference Proceedings 1, 2017, pp. 100001-100009, , https://doi.org/10.1063/1.4982318.

[50] S.R. Shirsath, S.S. Sable, S.G. Gaikwad, S.H. Sonawane, D.R. Saini, P.R. Gogate, Intensification of extraction of curcumin from Curcuma amada using ultrasound assisted approach: effect of different operating parameters, Ultrason. Sonochem. 38 (2017) 437-445, https://doi.org/10.1016/j.ultsonch.2017.03.040. 